\title{
Performance Measurement In The eCommerce Industry
}

Jamshed Mistry (E-mail: jjmistry@wpi.edu), Worcester Polytechnic Institute

\begin{abstract}
The Balanced Scorecard framework (BSC) developed by Kaplan and Norton (1992) has been widely accepted by most academics and adopted by numerous practitioners in industry. Despite being widely accepted by practitioners in industry, little extant research has focused on the BSC and little empirical analysis has focused on validating the model. This paper first develops performance measures specifically designed for the eCommerce industry by drawing on the BSC and other measures developed by practitioners. Next, the paper reports evidence of the utility of the BSC framework in measuring and monitoring the performance of e-commerce companies. The study utilizes an integrated Data Envelopment Analysis (DEA) model to examine and evaluate the relative efficiency of the measures identified within the BSC framework for measuring the performance of eCommerce companies. Finally, the study examines the effectiveness of the BSC framework in predicting the success or failure of eCommerce companies by focusing on three successful eCommerce and three eCommerce companies that subsequently failed.
\end{abstract}

\section{Introduction}

In the last decade, management accounting researchers have become increasingly interested in analyzing the impact of non-financial performance measures on the performance of the firm. As competition in the marketplace has intensified, non-financial performance measures have become progressively more important as new sources of relevant information (Hemmer, 1996). The need for planning, information and control systems that can assist managers in their decision-making has also stimulated the need for new non-financial measures of performance. This need has focused attention on developing new models to assist managers with their strategic decision-making, planning and control decisions (Banker and Johnston, 2000). One model that has generated attention in the past decade is the Balanced Scorecard model developed by Kaplan and Norton (1992). This framework emphasizes the need to measure and monitor the performance of companies within the broad framework of both financial and non-financial parameters of performance.

As a part of the new age economy, Business-to-Consumer companies or Dot-coms or e-retailers are among the new age companies that have revolutionized the marketplace. These new economy companies appear to defy the basic rules of business. The global reach of the Internet and the consequent bargaining power it has provided the worldwide customer has invalidated most of the older management practices. Dot-coms or eCommerce companies have necessitated the development of a whole new set of performance measurement parameters for monitoring and measuring their performance. For example, reach, click through ratio, hits, visits, number of subscribers, quick loading time, personalization, number of affiliates and navigation have been suggested as parameters that indicate the operational and marketing efficiency of these companies (Seybold, 2000).

Although the Balanced Scorecard model was initially proposed in 1992, and the model has been widely accepted by most practitioners, little empirical analysis has focused on validating the model. In this paper, four sets of performance measurement parameters specifically designed for eCommerce companies are developed, drawing on the Balanced Scorecard framework. Data Envelopment Analysis (DEA) using these measures is then employed to examine the efficiency of Balanced Scorecard parameters in measuring and monitoring the performance of eighteen eCommerce companies. Finally, six of the eighteen companies are analyzed to compare the three most successful companies with three that subsequently failed in order to examine the effectiveness of the Balanced Scorecard parameters in predicting bankruptcy. 


\section{Background and Significance}

In their pioneering research on measuring the performance of organizations, Kaplan and Norton (1992) describe the innovation of the balanced scorecard as follows:

"The balanced scorecard retains traditional financial measures. But financial measures tell the story of past events, an adequate story for industrial age companies for which investments in longterm capabilities and customer relationships were not critical for success. These financial measures are inadequate, however, for guiding and evaluating the journey that information age companies must make to create future value through investment in customers, suppliers, employees, processes, technology, and innovation."

Kaplan and Norton (1992) suggest a balanced scorecard, which requires managers to balance four different but linked perspectives in order to identify appropriate measures of performance. The first perspective represents (traditional) accounting measures that report the financial consequences of actions already taken. This financial perspective highlights how the company appears to shareholders and concentrates on measures relating to profitability and growth, cash flow and gearing. The Balanced Scorecard supplements these financial measures with three other perspectives dealing with (a) customers, (b) internal processes, and (c) the firm's innovation and learning record - all three areas that are important drivers of future financial performance. The customer perspective is designed to highlight the factors that really matter to customers such as value for money, time and performance. The internal business perspective is designed to focus on those critical business activities that must be performed in order to satisfy the expectations of its customers. These include cycle time, quality and efficiency of operations. The innovation and learning perspective highlights the fact that, in the face of intense competition, firms must make continual improvement and have the ability to introduce new products in the future. Thus, the four perspectives of the balanced scorecard can be summarized as follows:

Table 1: Balanced Scorecard Framework

\begin{tabular}{|l|l|}
\hline \multicolumn{1}{|c|}{ Perspective } & \multicolumn{1}{c|}{ Focus } \\
\hline Financial & How do we look to our stockholders? \\
\hline Internal & How can we improve the efficiency of operations? \\
\hline Customer & What do our existing and new customers want from us? \\
\hline Innovation and Learning & How can we continue to innovate and learn? \\
\hline
\end{tabular}

An automatic side benefit of this critical thinking is the development of a deeper understanding of the various dimensions of the business and what activities must be performed well if the firm is to achieve success. In turn, such measures can be valuable in external benchmarking exercises. In addition, by working closely with production, marketing and other staff to agree and obtain such information, the management accountant can help to bring together these disciplines and install a greater sense of purpose and focus. Kaplan and Norton (1992) argue that managers should not have to choose between financial and operational measures of performance. Rather, managers want a balanced presentation of both financial and non-financial measures.

Measuring the performance of eCommerce companies has always been a relatively difficult task. Practitioners and consultants have suggested different parameters to measure the success of these companies. For example, numbers of subscribers, reach (unique visitors), and revenue have been identified as relevant measures to assess the performance of these companies. In terms of marketing parameters, personalization and offering value to customers have been linked with the success of the eCommerce firms (Seybold, 2000). eCommerce firms have also focused on continuous innovation in order to integrate technology with offering customized tailor-made services to the customers. Through the integration of technology, one-on-one marketing, permission marketing and personalization have become necessary tools for any eCommerce company in order to stay competitive. The focus has been on integrating various offline and online processes to provide solutions to customer needs. eCommerce firms are presently using parameters such as revenue, click-through-ratios and other indirect parameters to measure their performance. Thus, in practice, eCommerce companies already measure their performance by using a mix of traditional and new parameters. 
Both academics and practitioners have attempted to apply the Balanced Scorecard concepts to eCommerce companies. These attempts differ from Kaplan's scorecard in terms of the perspectives and parameters. Launched in 1999, McKinsey's e-performance scorecard collects data about a variety of visitor, customer, and financial metrics (Agarwal, Arjona, and Lemmens, 2001). The scorecard comprises 21 indicators that measure performance both statically (at one point in time) and dynamically (over a period of time). These indicators are grouped into three categories - attraction, conversion, and retention - and then folded into the overall e-performance scorecard, which is a weighted average of the twenty-one indicators. The McKinsey scorecard highlights two key dimensions: the efficiency of costs (for example, the cost of attracting visitors to a site and of maintaining active customers) and the effectiveness of a site's operations (such as conversion rates, the rate at which the number of customers increases, and customer gross margins). Best practice in the eBusiness sector combines the lowest costs with the highest effectiveness.

In her book Customers.com, Seybold lists eight success factors for eCommerce companies (Seybold, 2000). These factors cover various aspects of the business but she suggests that the main focus should be the customer. While these factors are primarily related to the customer, other researchers focus on other areas of eCommerce such as Logistics. The future role of distribution and fulfillment has been summed up as follows: "eCommerce delivery will become the one area in which a business can truly distinguish itself. It will become the critical core competence. Its speed, quality and responsiveness may well become the decisive competitive factor, even where brands seem to be entrenched. And there are no multinational businesses and altogether very few businesses that are organized for it. Very few yet even think that way," (Drucker, 2000).

To summarize, from a practitioner or applied perspective, parameters that assess much more than financial performance have been consistently highlighted. The customer point of view and integration of technology to produce personalized web content for customers are considered important measures of performance in eCommerce companies. Processes, logistics, and technological innovations are other measures of performance for eCommerce companies that have been emphasized. The applied perspectives highlighted in this section suggest that the focus of practitioners is on measures such as technology, business model, web-site features, customer value and innovation rather than the core business perspective of generating economic value for the business. These non-financial measures are very consistent with those emphasized by Kaplan and Norton (1992) in their Balanced Scorecard approach to measure and monitor the performance of organizations.

Since the Balanced Scorecard Framework focuses simultaneously on both financial and non-financial measures of performance, it is considered particularly appropriate for eCommerce companies. Therefore, in this paper, the BSC is utilized to assess the performance of a sample of eCommerce companies. First, the framework is developed for application to eCommerce by selecting measures developed by practitioners to represent the three non-financial perspectives, i.e. the Customer, Internal, and Innovation dimensions. Then, the four sets of measures (1 financial, and 3 non-financial) are derived for a sample of 18 eCommerce companies that were active in 1999. DEA analysis is performed on these measures to examine the efficiency of these companies on each of the BSC perspectives.

As Kaplan and Norton (2001) suggest, performance measurement has consequences far beyond reporting on the past. They suggest that measurement creates a focus on the future as the measures chosen communicate important messages to all organizational units and employees. Thus, the DEA analysis is followed by a comparison of the efficiency of the financial and non-financial parameters for companies that remained successful in 2000-2001 with three companies that subsequently filed for bankruptcy. Based on these comparisons, it is argued that these Balanced Scorecard parameters can effectively help us to understand and explain the success and failure of the selected eCommerce companies. 


\section{Development of BSC dimensions for eCommerce companies}

In this section, performance indicators identified by practitioners in eCommerce, are selected to represent the four dimensions of Kaplan and Norton's (1992) BSC framework. The specific measures derived for each of the four dimensions are presented in Table 2 .

Table 2. eCommerce performance indicators for the BSC dimensions

\begin{tabular}{|c|c|c|c|c|c|}
\hline Perspective & \multicolumn{2}{|c|}{ Inputs } & \multicolumn{3}{c|}{ Outputs } \\
\hline Customer & $\begin{array}{c}\text { Marketing } \\
\text { Expenditure }\end{array}$ & $\begin{array}{c}\text { Number of } \\
\text { Affiliates }\end{array}$ & Revenue & $\begin{array}{c}\text { Number of } \\
\text { Customers }\end{array}$ & $\begin{array}{c}\text { Number of } \\
\text { visitors }\end{array}$ \\
\hline $\begin{array}{c}\text { Internal } \\
\text { Processes }\end{array}$ & $\begin{array}{c}\text { Number of } \\
\text { Employees }\end{array}$ & Financing & Revenue & $\begin{array}{c}\text { Number of } \\
\text { Customers }\end{array}$ & $\begin{array}{c}\text { Number of } \\
\text { visitors }\end{array}$ \\
\hline $\begin{array}{c}\text { Inn./Know. } \\
\text { Mgmt. }\end{array}$ & $\begin{array}{c}\text { Number of } \\
\text { Employees }\end{array}$ & $\begin{array}{c}\text { Tech./Dev. } \\
\text { Expenditure }\end{array}$ & Revenue & $\begin{array}{c}\text { Number of } \\
\text { Customers }\end{array}$ & \\
\hline Finance & Financing & Net Income & & Revenue & \\
\hline
\end{tabular}

Financial Dimension: The first perspective represents traditional accounting measures that report the financial consequences of actions already taken. This financial perspective highlights how the company appears to shareholders and concentrates on measures relating to profitability and growth, cash flow and gearing. Traditional financial measures include ROS (return on sales) and financing as a percentage of revenue. These measures are applicable to eCommerce companies and therefore, have been included as representing the financial perspective.

Customer dimension: The customer perspective is designed to highlight the factors that really matter to customers such as value for money, time, and performance. Numbers of unique visitors and customers are important performance indicators for eCommerce companies. Marketing expenditures and number of affiliates are used to generate visitors, some of whom will become customers and buy the products and services. Thus, potential inputs such as marketing expenditure and number of affiliates are assumed to generate number of visitors, number of customers, and sales revenues as outputs representing the customer dimension.

Internal processes dimension: The internal business perspective is designed to focus on those critical business activities that must be performed in order to satisfy the expectations of its customers. These include cycle time, quality, and efficiency of operations. It is argued that number of employees and available financing influences the cycle time, quality, and efficiency of operations and thus represent the internal processes dimension. More efficient use of these resources will impact the conversion factor (i.e. numbers of unique visitors who become customers). Hence, outputs are number of customers and sales revenues.

Innovation and learning dimension: The innovation and learning perspective highlights the fact that, in the face of intense competition, firms must make continual improvement and have the ability to introduce new products in the future. Development expenditure and number of employees are measures of the amount of resources that are allocated to develop new products and services and improvements in service quality. Thus, these are considered the inputs representing the innovation dimension to generate numbers of customers and revenue as outputs.

The financial and non-financial performance measures derived by applying the BSC to performance indicators developed by practitioners to assess eCommerce companies were then utilized to investigate empirically the utility of the framework and measures. The methodology of the empirical investigation is described in the following section. 


\section{Methodology}

\subsection{Sample}

The data were obtained from the eCommerce Almanac data set collected by the Intermarket Group. This almanac from the Intermarket group compiles exhaustive information about eCommerce companies and includes financial, marketing, operational and other information that can be categorized into the balanced scorecard framework. The original data set includes eighty-two eCommerce companies. However, data on all the performance measures that were derived for each of the four BSC dimensions were available for only eighteen companies. Hence, the final sample consists of these eighteen eCommerce companies.

In order to analyze the relevance of the balanced scorecard in differentiating between both successful and failed eCommerce companies, it was very important to include companies that were active and functioning companies at the time of data collection. Hence, the sample set includes data from the year 1999 when all of the eighteen companies were in operation and were going concerns (i.e., companies that were expected to be in operation in the near future). In the first set of analysis, DEA methodology is applied to measures used to represent each of the four BSC dimensions. In the second set of the analysis, three companies that subsequently filed for bankruptcy (in 2000-2001) were chosen for analysis and compared with three companies that were highly ranked in the DEA analysis conducted on all 18 companies based on data from 1999.

\subsection{Plan of Analysis}

The primary purpose of the empirical analysis was to examine if the performance measures derived from the Balanced Scorecard were useful in differentiating between successful and subsequently unsuccessful eCommerce companies. In the first set of analysis, DEA methodology was utilized to examine the efficiency of all eighteen companies on each of the four dimensions. DEA methodology can be briefly described as follows:

Through the optimization for each individual unit, DEA yields an efficient frontier that represents and estimates the relations among the multiple performance measures (Charnes, Cooper and Rhodes, 1978).

Suppose we have a set of $n$ decision making units (DMUs) (e.g., companies), $D M U_{j}(j=1, \ldots, \mathrm{n})$ and let $x_{i}(i=1, \ldots, m)$ be the $m$ input performance measures where smaller values are preferred, e.g., cost measures and $y_{r}(r=1, \ldots, s)$ be the s output performance measures where larger values are preferred, e.g., revenue. Thus, we have $\mathrm{m}+\mathrm{s}$ performance measures for the $n$ DMUs. Further, we have $x_{i j}$ as the observed value on the ith input performance measure and $y_{r j}$ as the observed value on the $r$ th output performance measure.

Based upon the observations, we have the following DEA model for evaluating the relative efficiency of $D M U_{o}$ among other DMUs:

$$
\begin{array}{ll}
\min \theta & \\
\text { s.t. } & \sum_{j=1}^{n} \lambda_{j} x_{i j} \leq \theta x_{i o} \quad \mathrm{i}=1, \ldots, m \\
& \sum_{j=1}^{n} \lambda_{j} y_{r j} \geq y_{r o} \quad \mathrm{r}=1, \ldots, s \\
& \sum_{j=1}^{n} \lambda_{j}=1 \\
& \lambda_{j} \geq 0, \quad j=1, \ldots, n
\end{array}
$$


Model (1) is called variable returns to scale (VRS) model in DEA (Banker, Charnes and Cooper, 1984). Model (1) is input-oriented, since it minimizes inputs while keeping the outputs at their current levels. We can have an output-oriented model, which maximizes outputs while keeping the inputs at their current levels.

$$
\begin{array}{ll}
\max & \\
\text { s.t. } & \sum_{j=1}^{n} \lambda_{j} x_{i j} \leq x_{i o} \quad \mathrm{i}=1, \ldots, m \\
& \sum_{j=1}^{n} \lambda_{j} y_{r j} \geq \phi y_{r o} \quad \mathrm{r}=1, \ldots, s \\
& \sum_{j=1}^{n} \lambda_{j}=1 \\
& \lambda_{j} \geq 0, \quad j=1, \ldots, n
\end{array}
$$
DEA models.

The above two models allow us to deal with negative inputs and outputs. See Zhu (2002) for additional

\section{Results}

In the first set of analyses, DEA methodology was applied and input and output-oriented models were run to assess the efficiency of eighteen E-commerce companies on each of the four dimensions of the BSC. While the financial perspective utilizes traditional financial measures, the customer, internal processes and innovation dimensions utilize non-financial measures. On each dimension, the companies have been presented based on their decreasing order of efficiency scores for each dimension (see tables 3-6). For example, in the financial dimension, 1 is the most efficient (Amazon.com) and 1.23 is the least efficient (Webvan) (See Table 3) as an output-oriented model was utilized, while in the customer dimension 1 is the most efficient (again Amazon.com) and 0.14 is the least efficient (PlanetRX.com) as an input-oriented model was used.

Since our objective was to examine the utility of the DEA efficiency scores in predicting future success or failure of the companies, we identified three companies that subsequently failed and three that remained successful and located these six companies in the rank-ordered list in Table 3. The three companies that remained active in 2000-2001 were Amazon.com, eBay, and Priceline.com. The three companies that subsequently failed were Webvan.com, PlanetRx.com, and Furniture.com

As evident from Table 3, two successful companies (Amazon.com and eBay) and one of the ones that subsequently failed (Furniture.com), emerge as financially efficient in 1999, falling among the seven companies with the highest rank-orders (1-7). The two companies that subsequently failed (Webvan and PlanetRX.com) and one of the successful companies fall among the lowest ranked companies. Webvan is the lowest ranked with Priceline.com also showing that it does not appear to be a financially efficient company and PlanetRX.com falling within the six lowest ranked firms. Hence, the results from the financial dimension are mixed and do not appear to present the full picture.
Table 3: Financial Dimension

\begin{tabular}{|l|c|}
\hline \multicolumn{1}{|c|}{$\begin{array}{c}\text { DMU } \\
\text { Name }\end{array}$} & $\begin{array}{c}\text { Input-oriented } \\
\text { VRS Efficiency }\end{array}$ \\
\hline Amazon.com & 1.00000 \\
\hline eBay & 1.00000 \\
\hline E*Trade & 1.00000 \\
\hline iPrint & 1.03084 \\
\hline Peapod & 1.05091 \\
\hline Outpost.com & 1.06077 \\
\hline Furniture.com & 1.07603 \\
\hline iOwn & 1.08086 \\
\hline PetsMart.com & 1.08399 \\
\hline 1-800-Flowers & 1.08678 \\
\hline CarsDirect.com & 1.11428 \\
\hline NextCard & 1.12178 \\
\hline PlanetRX.com & 1.15505 \\
\hline Buy.com & 1.15614 \\
\hline Cdnow & 1.19104 \\
\hline Beyond.com & 1.20081 \\
\hline Priceline.com & 1.20808 \\
\hline Webvan & 1.22904 \\
\hline
\end{tabular}


From the customer perspective (please see Table 4), it can be noted that the three successful companies (Amazon.com, eBay, and Priceline.com) are highly efficient (scores between .93 and 1.0), whereas two of the three failed companies (Furniture.com and PlanetRx.com) rank lowest on efficiency with scores ranging from 0.22 and 0.14 , respectively, in the Customer perspective. The other failed company, Webvan falls in the middle range of efficiency (0.61). Apparently, these efficiency scores based on data from 1999 when all the companies were active, do differentiate between the ones that remained successful and those that subsequently failed.

On the innovation and learning perspective, again the efficiency scores appear to discriminate between the subsequently successful and unsuccessful companies (Table 5). All three successful companies fall within the top 7 rank-ordered companies and have efficiency scores ranging from .79 to 1.0. On the other hand, the three companies that subsequently failed fall in the lowest six ranks ordered companies, with efficiency scores less than.38.

As evident from Table 6, the results are mixed on the internal process perspective (as they were on the financial dimension). The two most successful companies (Amazon.com and ebay.com) were optimally efficient once again (1.0), while one failed company (Furniture.com) also had high efficiency scores (.89). One successful and one failed company (Priceline.com and PlanetRx.com) had medium efficiency levels ( 0.68 and 0.51 ), and one failed company (Webvan) had the lowest efficiency score of 0.08 .

Table 5: Innovation \& Learning Dimension

\begin{tabular}{|c|c|}
\hline $\begin{array}{c}\text { DMU } \\
\text { Name }\end{array}$ & $\begin{array}{c}\text { Input-oriented } \\
\text { VRS Efficiency }\end{array}$ \\
\hline Amazon.com & $\mathbf{1 . 0 0 0 0 0}$ \\
\hline eBay & $\mathbf{1 . 0 0 0 0 0}$ \\
\hline Buy.com & $\mathbf{1 . 0 0 0 0 0}$ \\
\hline CarsDirect.com & $\mathbf{1 . 0 0 0 0 0}$ \\
\hline 1-800-Flowers & $\mathbf{1 . 0 0 0 0 0}$ \\
\hline PetsMart.com & $\mathbf{1 . 0 0 0 0 0}$ \\
\hline Priceline.com & $\mathbf{0 . 7 9 8 0 0}$ \\
\hline Outpost.com & $\mathbf{0 . 7 7 8 0 0}$ \\
\hline iPrint & $\mathbf{0 . 7 2 5 6 1}$ \\
\hline Peapod & $\mathbf{0 . 6 3 1 1 2}$ \\
\hline Beyond.com & $\mathbf{0 . 6 2 0 2 9}$ \\
\hline Cdnow & $\mathbf{0 . 3 8 9 8 1}$ \\
\hline Furniture.com & $\mathbf{0 . 3 8 2 7 4}$ \\
\hline iOwn & $\mathbf{0 . 2 5 4 6 8}$ \\
\hline NextCard & $\mathbf{0 . 2 1 1 0 3}$ \\
\hline PlanetRX.com & $\mathbf{0 . 1 9 8 4 0}$ \\
\hline E*Trade & $\mathbf{0 . 1 7 8 1 3}$ \\
\hline Webvan & $\mathbf{0 . 1 5 6 8 8}$ \\
\hline
\end{tabular}

Table 4: Customer Dimension

\begin{tabular}{|l|c|}
\hline \multicolumn{1}{|c|}{$\begin{array}{c}\text { DMU } \\
\text { Name }\end{array}$} & $\begin{array}{c}\text { Input-oriented } \\
\text { VRS Efficiency }\end{array}$ \\
\hline Amazon.com & 1.00000 \\
\hline eBay & 1.00000 \\
\hline Buy.com & 1.00000 \\
\hline iPrint & 1.00000 \\
\hline Peapod & 1.00000 \\
\hline Priceline.com & 0.93173 \\
\hline 1-800-Flowers & 0.82261 \\
\hline Webvan & $\mathbf{0 . 6 1 0 2 1}$ \\
\hline NextCard & $\mathbf{0 . 5 3 4 9 4}$ \\
\hline Outpost.com & $\mathbf{0 . 5 3 1 1 2}$ \\
\hline Cdnow & $\mathbf{0 . 4 8 5 7 6}$ \\
\hline CarsDirect.com & $\mathbf{0 . 3 8 8 2 8}$ \\
\hline iOwn & 0.37709 \\
\hline Beyond.com & 0.31434 \\
\hline E*Trade & 0.26294 \\
\hline Furniture.com & 0.22682 \\
\hline PetsMart.com & 0.22603 \\
\hline PlanetRX.com & $\mathbf{0 . 1 3 9 1 6}$ \\
\hline & \\
\hline
\end{tabular}

Table 6: Internal Process Dimension

\begin{tabular}{|l|c|}
\hline \multicolumn{1}{|c|}{$\begin{array}{c}\text { DMU } \\
\text { Name }\end{array}$} & $\begin{array}{c}\text { Input-oriented } \\
\text { VRS Efficiency }\end{array}$ \\
\hline Amazon.com & $\mathbf{1 . 0 0 0 0 0}$ \\
\hline eBay & $\mathbf{1 . 0 0 0 0 0}$ \\
\hline Buy.com & $\mathbf{1 . 0 0 0 0 0}$ \\
\hline Cdnow & $\mathbf{1 . 0 0 0 0 0}$ \\
\hline iOwn & $\mathbf{1 . 0 0 0 0 0}$ \\
\hline iPrint & $\mathbf{1 . 0 0 0 0 0}$ \\
\hline 1-800-Flowers & $\mathbf{1 . 0 0 0 0 0}$ \\
\hline PetsMart.com & $\mathbf{1 . 0 0 0 0 0}$ \\
\hline Furniture.com & $\mathbf{0 . 8 9 2 1 7}$ \\
\hline Outpost.com & $\mathbf{0 . 8 4 9 9 3}$ \\
\hline Priceline.com & $\mathbf{0 . 6 8 2 0 0}$ \\
\hline Beyond.com & $\mathbf{0 . 5 8 5 2 3}$ \\
\hline PlanetRX.com & $\mathbf{0 . 5 1 0 9 2}$ \\
\hline Peapod & $\mathbf{0 . 4 9 0 8 4}$ \\
\hline NextCard & $\mathbf{0 . 4 4 6 1 5}$ \\
\hline CarsDirect.com & $\mathbf{0 . 1 8 9 8 6}$ \\
\hline E*Trade & $\mathbf{0 . 1 7 8 1 3}$ \\
\hline Webvan & $\mathbf{0 . 0 8 4 0 1}$ \\
\hline
\end{tabular}


In summary, DEA efficiency scores representing the customer dimension and the innovation dimension (that are particularly relevant for eCommerce companies) do differentiate between the three successful and the three subsequently failed eCommerce companies. The results on the financial dimension and the internal processes dimension (representing more traditional dimensions of company performance) are mixed, although the two most successful companies Amazon.com and eBay are consistently ranked first and second.

\section{Comparison Of Key Performance Indicators For Successful And Failed Companies}

In the next set of analyses, the three companies that remained successful were compared to the three companies that subsequently failed (filed for bankruptcy in 2000-01) on key performance indicators (KPI) representing the four dimensions of the BSC (see Table 7 for the key performance indicators).

Table 7: Key Performance Indicators for the Four BSC dimensions

\begin{tabular}{|l|l|l|l|}
\hline \multicolumn{1}{|c|}{ Perspective } & \multicolumn{3}{|c|}{ Key Performance Indicators } \\
\hline Customer & $\begin{array}{l}\text { Customer } \\
\text { Conversion Factor }\end{array}$ & $\begin{array}{l}\text { Customer Profitability } \\
\text { Profitability per customer }\end{array}$ & $\begin{array}{l}\text { Customer contribution } \\
\text { Revenue per customer }\end{array}$ \\
\hline Internal Process & $\begin{array}{l}\text { Customer } \\
\text { Conversion Factor }\end{array}$ & $\begin{array}{l}\text { Revenue/ } \\
\text { Technical/Dev. expenditure }\end{array}$ & $\begin{array}{l}\text { Revenue/ } \\
\text { Marketing expenditure }\end{array}$ \\
\hline Innovation & $\begin{array}{l}\text { Employee Value } \\
\text { Revenue/Employee }\end{array}$ & $\begin{array}{l}\text { Employee Profitability } \\
\text { Profitability/Employee }\end{array}$ & $\begin{array}{l}\text { Customers/ } \\
\text { Technical-Dev. expenditure }\end{array}$ \\
\hline Finance & Funding & Revenues & Net income \\
\hline
\end{tabular}

These key performance indicators were selected for each dimension based on practitioner measures and measures typically utilized in industry. Data on the key performance indicators representing each of the four BSC dimensions is presented for the six companies selected for comparison - i.e. the three successful companies and the three that subsequently failed (see Tables 8-11).

As evident from Table 8 on the financial dimension, although the funding and revenue KPI's for the three successful companies are generally higher than for the three failed companies, five of the six companies show no profit (negative profitability). Although some eCommerce companies have started posting profits lately, this was typical in the 1999-2000 time frame, with only eBay posting a profit for the current year.

Table 8: Financial Dimension: KPI Results

\begin{tabular}{|l|r|r|r|}
\hline \multicolumn{1}{|c|}{ DMU } & Funding & Revenue & Profit \\
\hline Amazon.com & 2680.00 & 1640.00 & -719.70 \\
\hline eBay & 823.90 & 224.70 & 10.83 \\
\hline Priceline & 1592.00 & 482.40 & -152.60 \\
\hline Furniture & 84.00 & 10.90 & -46.46 \\
\hline PlanetRx & 144.50 & 8.99 & -98.01 \\
\hline Webvan & 966.03 & 13.31 & -144.60 \\
\hline
\end{tabular}

Thus, based on the KPIs for the financial dimension along, it would not have been possible to predict that any of the companies would be successful in subsequent years. Results on the KPIs for the financial perspective are therefore consistent with the results from the previous analysis using DEA methodology on the financial dimension, indicating that this dimension does not provide a complete picture of the performance of eCommerce companies.

The KPIs representing the Customer dimension, however, do add important information regarding the performance of the companies. As can be seen from Table 9, two of the KPI's (customer conversion factor and 
profitability per customer) clearly differentiate between the successful and failed companies, with the conversion factor for the three successful companies ranging from 5.9 to 9.5 and the conversion factor for the failed firms ranging from 1.5 to 2.8 . The profitability per customer ranges from a loss of $\$(40)$ to a profit of $\$ 1$ per customer for the successful firms while the results for the unsuccessful firms depict a loss ranging from $\$(179)$ to $\$(3,077)$ per customer. The data on the revenue per customer KPI however is mixed - the revenue per customer for two of the successful firms varies from is relatively higher, though one of the failed firms shows the highest revenue per customer (Webvan). Although the revenue per customer for Webvan appears to be relatively high, the loss per customer of $\$(3,077)$ depicts a different story.

Table 9: Customer Dimension: KPI Results:

\begin{tabular}{|l|c|c|c|}
\hline \multicolumn{1}{|c|}{ DMU } & $\begin{array}{c}\text { Customer } \\
\text { Conversion Factor }\end{array}$ & Revenue/Customer & Profitability/Customer \\
\hline Amazon.com & 9.50 & 97 & -42 \\
\hline eBay & 5.94 & 22 & -40 \\
\hline Priceline & 7.16 & 127 & -179 \\
\hline Furniture & 2.44 & 42 & -386 \\
\hline PlanetRx & 1.48 & 35 & -3077 \\
\hline Webvan & 2.80 & 283 & \\
\hline
\end{tabular}

The KPIs representing the Innovation dimension also add relevant information regarding the performance of the companies. Two of the three KPI's clearly differentiate between the successful and failed companies (see Table 10). The revenue per employee KPI is visibly higher (ranging from $\$ 215,789$ to $\$ 1,276,190$ ) for the successful companies and lower for the failed ones (ranging from $\$ 23,051$ to $\$ 51,192$ ). The profit per employee KPI does not differentiate as much because five out of the six firms are not profitable. However, the customer per development expenditure does differentiate as it depicts a higher ratio ranging from 106 to 421 for the successful firms and a markedly lower 3 to 39 ratio for the three firms that subsequently failed.

Table 10: Innovation Perspective: KPI Results

\begin{tabular}{|l|c|c|c|}
\hline \multicolumn{1}{|c|}{ DMU } & Revenue/Employee & Profitability/Employee & $\begin{array}{c}\text { Customer/Development } \\
\text { expenditure ('000) }\end{array}$ \\
\hline Amazon.com & 215789 & -93680 & 106 \\
\hline eBay & 741700 & 36093 & 221 \\
\hline Priceline & 1276190 & -403704 & 39 \\
\hline Furniture & 51192 & -218122 & 20 \\
\hline PlanetRx & 23051 & -251318 & 3 \\
\hline Webvan & 47706 & -518280 & \\
\hline
\end{tabular}

For the Internal process dimension, all three key performance indicators very clearly differentiate between the successful and failed companies (see Table 11). The conversion factor KPI ranges from 5.9 to 9.5 for the successful firms and ranges from 1.5 to 2.8 for the failed firms. The revenue per development expenditure also shows that there is a marked difference since the scores range from $\$ 9.4$ to 34.5 for the successful firms and only range from $\$ 0.7$ to $\$ 1.6$ for the failed firms. Finally, the revenue per marketing expenditure KPI also shows a marked difference in that the KPI's for the successful firms range from $\$ 2.3$ to $\$ 6.1$ while the KPI's for the failed firms range from $\$ 0.2$ to $\$ 1.1$. 
Table 11: Internal Process Dimension: KPI

\begin{tabular}{|l|c|c|c|}
\hline \multicolumn{1}{|c|}{ DMU } & Customer conversion factor & $\begin{array}{c}\text { Revenue/Marketing } \\
\text { Expenditure }\end{array}$ & $\begin{array}{c}\text { Revenue/Development } \\
\text { Expenditure }\end{array}$ \\
\hline Amazon.com & 9.51 & 4.00 & 10.30 \\
\hline eBay & 5.94 & 2.30 & 9.40 \\
\hline Priceline & 7.16 & 6.10 & 1.60 \\
\hline Furniture & 2.44 & 0.30 & 0.70 \\
\hline PlanetRx & 1.48 & 0.20 & 0.90 \\
\hline Webvan & 2.80 & 1.10 & \\
\hline
\end{tabular}

\section{Conclusion}

In conclusion, results from the two types of analyses (DEA and KPI methodology) suggest that the financial dimension of the Balanced Scorecard framework provides insufficient information to differentiate between the eCommerce companies that remained successful and those that subsequently failed. The results of the DEA analysis were mixed, while the KPI analysis indicated that five out of the six firms chosen could fail (due to negative earnings) in the near future.

Including the non-financial dimensions of the Balanced Scorecard framework provides a much more complete picture of the performance of the selected companies, based on which it would have been possible to predict subsequent success or failure. In both analyses (DEA and KPI methodology), the customer and innovation and learning dimensions enable differentiation between successful and subsequently failed eCommerce firms. On the internal process dimension, although the DEA analysis does not differentiate clearly between the successful and failed companies, the KPIs clearly differentiate between the two sets of companies. Overall, these results show that the customer and innovation and learning dimensions are able to differentiate between eCommerce companies with the potential for continued success and those that are likely to fail. The fact that these dimensions are especially important for eCommerce companies is consistent with conventional wisdom. The results therefore underscore the importance and relevance of the Balanced Scorecard framework for the performance measurement of eCommerce companies.

\section{References}

1. Agarwal, V., Arjona L. D., and Lemmens R. 2001, "McKinsey B2C e-Performance scorecard", The McKinsey Quarterly, Number 1: 20-32.

2. Banker, R.D., A. Charnes, and W. W. Cooper. 1984, "Some models for estimating technical and scale inefficiencies in data envelopment analysis", Management Science, 30, 1078-1092.

3. and H. H. Johnston. 1995. "An empirical study of the business value of the U. S. airlines' computerized reservations system", Journal of Organizational Computing, 5 (3): 255-275.

4. Charnes, A., W. W. Cooper, and E. Rhodes. 1978. "Measuring the efficiency of decision making units", European Journal of Operational Research, 2 (6): 429-444.

5. Drucker, P. 2000. "Can eCommerce deliver? The world in 2000", The Economist Publications, London.

6. Hemmer, T. 1996. "On the design and choice of 'modern' management accounting measures", Journal of Management Accounting Research, 8: 87-116.

7. Kaplan, R. S. and D. P. Norton. 1992. "The Balanced Scorecard - Measures that drive performance", Harvard Business Review, Jan-Feb.: 71-79.

8. 2001. "Transforming the balanced scorecard from performance measurement to strategic management: Part 1", Accounting Horizons, 15: 87-104.

9. Seybold, P. B. and R. Marshak, 2000. Customers. Com: How to create a profitable business strategy for the internet and beyond, Random House. Audio Books, U. K.

10. Zhu, Joe. 2002. Quantitative Models for Performance Evaluation and Benchmarking: Data Envelopment Analysis with Spreadsheets, Kluwer Academic Publishers, Netherlands. 